\title{
President's Message: Reflections on LITA's Past and Future
}

When I reached out to ITAL Editor Bob Gerrity about my first President's Column, he graciously provided copies of past LITA Presidents' columns to get me started. It reminded me once again of the illustrious company I am in, starting with Stephen R. Salmon, the first president of the Information Services and Automation Division, as we were known until 1977. I am proud to be at the head of LITA as it begins to celebrate its $50^{\text {th }}$ Anniversary year.

A half century ago when LITA was founded the world was experiencing an era of profound technological change. The US and Soviet Union were battling to be first in the Space Race, and an increasing number of world powers were engaging in nuclear testing. While Civil Rights demonstrations and the fighting in Vietnam dominated the news, we were imagining peace via the technologically-driven future depicted in a new TV series called Star Trek. With TV focused on the stars, we were able to go to the movies and explore the strange new world of inner space in Fantastic Voyage. Technology was poised to enter our daily lives as well, with Diebold demonstrating the first ATM $^{1}$ and Ralph $\mathrm{H}$. Baer writing the 4-page paper that would lay the foundation for the video game industry. ${ }^{2}$

Heady times for technology indeed, and the fact that Libraries were sufficiently advanced to require an Association dedicated to supporting technologists is hardly surprising. By the time of LITA's founding at the 1966 Midwinter Meeting in Chicago, library automation had been in development for over a decade. ${ }^{3}$ MARC was just being invented, with the first tapes from the Library of Congress scheduled to go to the sixteen pilot libraries later that year. Membership in the only organization that existed, the Committee on Library Automation (COLA), was restricted to the handful of professionals who either developed or managed existing library systems.

But technology was beginning to impact many more librarians than just those rarified few. According to President Salmon, "It was clear that large numbers of librarians who didn't meet COLA's standards for membership were in need of information on library automation and wanted leadership."4 The first meeting of our Division on July 14, 1966 at the ALA Annual Conference in New York was attended by several hundred librarians interested in information sharing, technology standards, and technology training for library staff. This group created the first mission, vision, and bylaws that set us on a 50 -year path of success.

LITA is well positioned to take the first steps into our next 50 years. Thanks to the efforts of last year's LITA Board, we are on the verge of adopting a new two-year strategic plan that is designed

Aimee Fifarek (aimee.fifarek@phoenix.gov) is LITA President 2016-17 and Deputy Director for Customer Support, IT and Digital Initiatives at Phoenix Public Library, Phoenix, AZ. 
to guide us through the current transitional period. It will be accompanied by a tactical plan that will allow us to document our accomplishments and set the stage for an ongoing culture of continuous planning. Also, Jenny Levine has proven to be extremely capable as she completes her first year as LITA Executive Director. She has just the right combination of ALA experience, technology know-how, and calm competence to guide us through the retooling and reimagining that is required to take a middle-aged Association into the next phase of its life.

The four areas of focus in the new strategic plan will help us to balance our efforts between preserving the strengths of our past and adapting our organization for a successful future. The first area of focus, Member Engagement, shows that our primary commitment needs to be to LITA members. Without you, LITA would not exist. One of the key efforts is to increase the value of LITA for members who are unable to travel to conferences. With travel budgets down and staying low, online member engagement is an area all of ALA needs to improve, and who better to lead in this area than LITA. The next area, Organizational Sustainability, is all about keeping the infrastructure of the organization strong, much of which happens in the domain of LITA staff. Budgeting, quality communication, and strategic planning all live here.

The section on Education and Professional Development recognizes the important role that webinars, online courses, online journal, and print publications play in allowing LITA members to share their knowledge on both cutting edge and practical topics with the rest of the Association and ALA in general. We are already doing great work here and we need to better support and expand these efforts.

The last focus area, Advocacy and Information Policy, represents a future growth area for LITA. Now that everyone in the library world "does" technology to a certain extent, LITA needs to think about how we will differentiate ourselves as outside competencies increase. Our advantage is that we have been doing and thinking about technology for much longer than anyone else. With our vast wealth of experience, it's appropriate that we work to become thought leaders and implementers in the information policy realm.

In this, as always, we return to where we started: our members. LITA has thrived over the last 50 years because of this, our most important resource. LITA was founded on the concept of sharing information about technology through conversation, publications, and knowledge creation. We endure because you, the committed, passionate information professionals are willing to share what you know with those who come after. And like our founders, there are always individuals who are willing to take on the mantle of leadership, whether through getting elected to LITA Board, becoming a Committee or Interest Group Chair, serving in key editorial roles for our monographs, journal, and blog, or joining the all-important LITA Staff. Thanks to all of you who make LITA's future happen every day. I am proud to be in your company. 


\section{REFERENCES}

1. Alan Taylor, “50 years ago: a look back at 1966," The Atlantic Photo, March 23, 2016, http://www.theatlantic.com/photo/2016/03/50-years-ago-a-look-back-at-1966/475074/, Photo 46.

2. “Take me back to August 30, 1966," http://takemeback.to/30-August-1966\#.V8SzItLrtaQ.

3. "Library Technology Timeline," http://web.york.cuny.edu/ valero/timeline_reference_citations.htm.

4. Stephen R. Salmon, "LITA's First 25 Years, a Brief History," http://www.ala.org/lita/about/history/1st25years. 